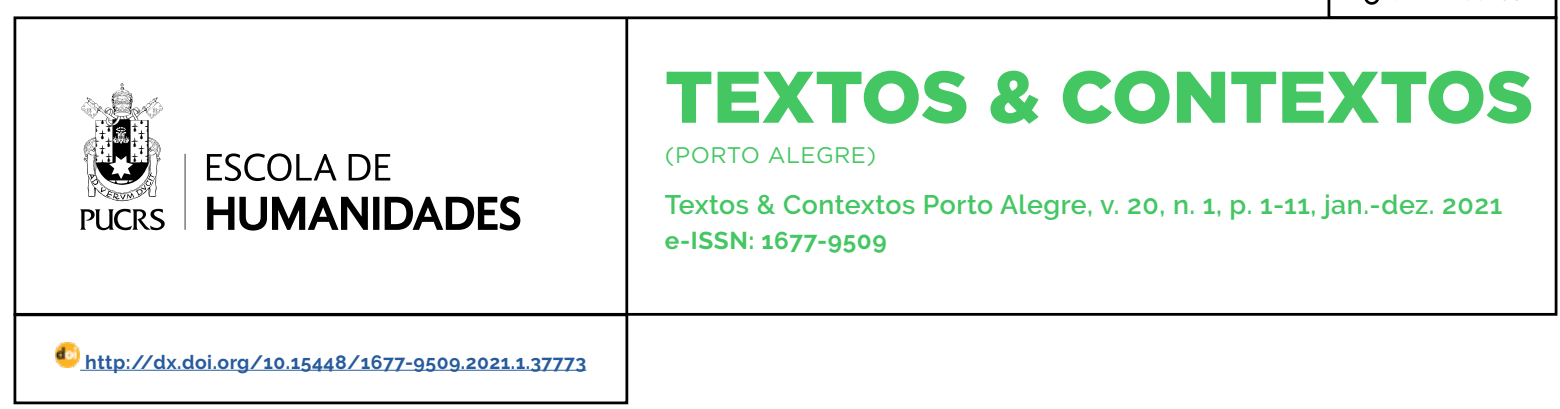

SEÇÃO: ARTIGOS E ENSAIOS

\title{
Regime stretching para proteger migrantes forçados no Brasil
}

Regime stretching to protect forced migrants in Brazil

\author{
Andrea Pacheco \\ Pacífico $^{1}$ \\ orcid.org/0000-0002-2744-7166 \\ apacifico@ccbsa.uepb.edu.br

\section{Thalita Franciely de \\ Melo Silva ${ }^{1}$ \\ orcid.org/0000-0002-9865-5229 \\ thalita.fmelo@gmail.com}

\section{Paulo Roberto Loyolla \\ Kuhlmann ${ }^{1}$ \\ orcid.org/0000-0001-7821-9086 prlkuhlm@gmail.com}

Recebido em: 21 abr. 2020 Aprovado em: 10 jul. 2021. Publicado em: 3 nov. 2021.

\section{(c) (1)}

Artigo está licenciado sob forma de uma licença Creative Commons Atribuicão 4.0 Internacional.
Resumo: O Brasil é membro do Regime Internacional dos Refugiados, tendo incorporado a Convenção Relativa para o Estatuto dos Refugiados de 1951 ao seu ordenamento jurídico com a Lei n. 9474/97. Ademais, avança na proteção humanitária baseada nos direitos humanos aos deslocados ambientais internacionais, a refugiados em massa e a migrantes econômicos (Lei de Migração n. 13.445/2017). Este artigo analisa a forma como a teoria de regime stretching proposta por Betts (2010) pode ser utilizada para explicar como o regime internacional de refugiados é alargado em nivel de implementação local para se adequar e suprir as necessidades locais, sendo aplicado hibridamente no Brasil com regras, normas, instituições e politicas públicas divergentes para os diferentes tipos de deslocados no Brasil.

Palavras-chave: Refugiados. Deslocados ambientais. Brasil. Regime Stretching.

Abstract: Brazil is an International Refugee Regime member, having incorporated the 1951 Convention related to Refugee Status into its Legal Order with the Act 9474/97. Additionally, it advances in humanitarian protection based on human rights to international environmentally Displaced Persons, to huge flux of refugees and to economic migrants (Migration Act $n$. 13.445.2017). This article evaluates the way how the regime stretching theory proposed by Betts (2010) may be used to explain how the International Refugee Regime is enlarged in local implementation level to be adjusted and to supply local needs, being hybridly implemented in Brazil, with different rules, norms, institutions, and public policies to different types of displaced people in Brazil.

Keywords: Refugees. Environmentally Displaced persons. Brazil. Regime Stretching.

\section{Introdução}

A crise das migrações, voluntárias ou forçadas, é fato público em esfera global, não deixando de atingir o Brasil, haja vista a atual entrada maciça de venezuelanos no Brasil, trazendo consequências politicas (como leis de endurecimento de fronteiras e centros de detenção para migrantes), sociais (discriminação, xenofobia e diversas formas de crimes contra migrantes) e econômicas (como dificuldade de acesso ao mercado de trabalho, à habitação e exploração laboral) para países de origem, de trânsito e de destino.

O Brasil, país formado por imigrantes das mais diversas origens, desde africanos a europeus e asiáticos, enfrenta a crise migratória em todas as suas consequências, particularmente, nos tempos atuais, com a vinda de sírios, de haitianos, após o terremoto de 2010 e, considerando os deslocamentos internos, com a ausência de proteção aos "invisiveis", que se movem internamente, sendo resultado dos desastres ambientais do Rio Doce e de Brumadinho. 
Nesse sentido, embora o Brasil possua uma das leis de refugiado (Lei n. 9474, de 23 de Julho de 1997) mais avançadas do mundo, em que a definição convencional é ampliada para reconhecer como tal o indivíduo que foge de seu país em virtude de grave e da generalizada violação aos direitos humanos, os sírios, que recebem status jurídico de refugiados no Brasil, com visto humanitário aplicado coletivamente, encontram dificuldades de integração, sentindo-se desprotegidos no país e sofrendo com violações aos direitos humanos, em virtude, basicamente, da falta de políticas públicas de integração adequadas e eficientes. O mesmo ocorre com os haitianos vindos após o terremoto de 2010, ou seja, deslocados ambientais que receberam o visto com residência permanente por motivo humanitário para fixação no país.

Um terceiro caso a ser analisado nesse artigo são os deslocados internos ambientais que tiveram que abandonar suas residências em virtude da tragédia ambiental da empresa Samarco no Rio Doce (e do mais recente desastre ambiental da represa de Brumadinho, em Minas Gerais), afetando milhares de familias que se encontram afastadas de seus lares e sem previsão de retorno, também devido à ausência de proteção especifica do governo brasileiro, que os ignora como tais, não os reconhecendo juridicamente como deslocados internos, evitando, assim responsabilização por obrigações contraídas em tratados e outras normas internacionais.

Portanto, embora membro do regime internacional de refugiados, tendo incorporado ao ordenamento jurídico interno a Convenção Relativa para o Estatuto dos Refugiados de 1951, o Protocolo Adicional de 1967 e as resoluções do Alto Comissariado das Nações Unidas para os Refugiados (ACNUR) que protegem refugiados e outras pessoas sob seu mandato, como os deslocados internos, o Brasil falha na proteção destes indivíduos vulneráveis. Ademais, embora os deslocados ambientais não sejam protegidos juridicamente pelo regime internacional implementado pelo ACNUR, o Brasil criou normas específicas para acolhê-los e protegê-los, apesar da implementação prática das normas mostrarem-se falhas. Saliente-se, aqui, que há normas sem vinculação juridica que protegem os deslocados internos ambientais, mas o Brasil se abstém, em nivel internacional de protegê-los como categoria de pessoas vulneráveis.

Em suma, este artigo visa mostrar as discrepâncias do governo brasileiro na proteção a refugiados (exemplo dos sírios), deslocados internos ambientais (exemplo dos deslocados do Rio Doce após o desastre ambiental da Samarco) e deslocados ambientais internacionais (exemplo dos haitianos no Brasil após o terremoto de 2010), confirmando a existência de um regime híbrido de proteção, ou seja, há regras, normas, instituições e políticas públicas (universalistas ou redistributivas e focadas ou distributivas) divergentes para os diferentes tipos de deslocados no Brasil, sejam eles refugiados convencionais, migrantes de sobrevivência, deslocados internos ou deslocados ambientais.

Para suprir e superar estas falhas, as autoras propõem a implementação, pelo governo brasileiro, da teoria de regime stretching desenvolvido por Alexander Betts (2010a, 2010b), entendida como "o grau pelo qual o escopo de um regime em nivel nacional ou local assume tarefas adicionais ou complementares não prescritas em nivel global" (BETTS, 2010b, p. 363). Portanto, altera, em âmbito de implementação nacional, o regime internacional de proteção a refugiados e outras pessoas sob mandato do ACNUR, adequando-o às necessidades locais, de forma padronizada. Esta inovação poderia ser realizada nesse momento atual, em que a sanção da nova Lei de Migração (Lei n. 13.445/2017) foi publicada e regulamentada pelo Decreto n. 9199/2017, instituindo a Lei de Migração Brasileira, com definição de direitos e deveres do migrante e do visitante no Brasil, regulamento da entrada e da permanência de estrangeiros no pais, estabelecimento de normas de proteção ao brasileiro no exterior etc.

\section{Proteção híbrida a refugiados e deslocados ambientais no Brasil}

Há, conforme Pacífico (2010, p. 376-377), políticas públicas redistributivas (ou universalistas), 
que visam redistribuir renda na forma de recursos e/ou financiar equipamentos e serviços públicos, como o acesso ao Bolsa Família, em que o governo pode retirar recursos do orçamento geral para aplicar em programas específicos. Além disso, há políticas distributivas (focadas), que possuem objetivos pontuais ou setoriais ligados à oferta de equipamentos e de serviços públicos financiados pela sociedade em geral, via orçamento público, beneficiando pequenos grupos ou indivíduos de diversas classes sociais, como programas assistenciais de emergência para enchentes e secas.

A proteção híbrida a migrantes, deslocados e refugiados do governo brasileiro pode ser comparada à proteção jurídica fornecida aos congoleses, sírios, haitianos e ganeses (CORREA et al., 2015). Quanto aos dois primeiros, é importante mencionar que eles foram acolhidos como refugiados convencionais, embora as solicitações dos congoleses tenham sido avaliadas individualmente e os sírios tenham sido reconhecidos prima facie. Quanto aos dois últimos, enquadram-se no conceito de migrantes de sobrevivência (BETTS, 2013), tendo os haitianos, de forma ad hoc, recebido visto permanente por motivo humanitário, conforme Resolução n. 97/2012 (BRASIL, 2012) do Conselho Nacional de Imigração (CNIg), e os ganeses, nem foram considerados refugiados convencionais nem receberam proteção ad hoc pelo governo brasileiro.

Nesse sentido, importa lembrar que, a Convenção Relativa ao Estatuto dos Refugiados de 1951 (Convenção de 1951), em seu artigo $1^{\circ}, a, \S$ $2^{\circ}$, define refugiado como:

toda pessoa que, em consequência dos acontecimentos ocorridos antes de $1^{\circ}$ de janeiro de 1951 e temendo ser perseguida por motivos de raça, religião, nacionalidade, grupo social ou opiniões políticas, se encontra fora do país de sua nacionalidade e que não pode ou, em virtude desse temor, não quer valer-se da proteção desse país, ou que, se não tem nacionalidade e se encontra fora do país no qual tinha sua residência habitual em consequência de tais acontecimentos, não pode ou, devido ao referido temor, não quer voltar a ele (ACNUR, 1951).

Vale ressaltar, ainda, que as cláusulas geográficas e temporais foram retiradas no Protocolo
Adicional de 1967 (ACNUR, 1967), possibilitando que qualquer pessoa, independentemente da data de 1 de janeiro de 1951 e da localização, goze desse instrumento em sua totalidade.

No âmbito da América Latina, a Declaração de Cartagena de 1984 (ACNUR, 1984) ampliou, na Parte III de seu terceiro parágrafo, a definição de refugiados, já consagrada pela Convenção de 1951 e pelo Protocolo Adicional de 1967, ao incluir pessoas que deixaram seus países porque sua vida, segurança ou liberdade foram ameaçadas, em decorrência da violência generalizada, agressão estrangeira, conflitos internos, violação massiva dos direitos humanos ou outras circunstâncias que perturbaram gravemente a ordem pública.

Os deslocados ambientais, contudo, são uma categoria de pessoas que não se encontram abarcados na definição da Convenção de 1951, tampouco no Protocolo Adicional de 1967. Estas pessoas são forçadas a se deslocarem de sua terra de origem em decorrência de mudanças climáticas ou alterações no meio ambiente, tais como secas intensas, desertificação, esgotamento do solo, enchentes, aumento do nível do mar ou eventos sazonais como as monções, erupção de vulcões etc., sendo chamados de refugiados ambientais, refugiados de desastre, pessoa ambientalmente deslocada, refugiados climáticos, entre outros (SOUZA, 2012; PACÍFICO; GAUDÊNCIO, 2014).

Os deslocados internos, de acordo com o parágrafo segundo da introdução dos Princípios Orientadores Relativos aos Deslocados Internos de 1998 (ONU, 1998), define o que segue, no item 2 de sua introdução:

são as pessoas, ou grupos de pessoas, forçadas ou obrigadas a fugir ou abandonar as suas casas ou seus locais de residência habituais, particularmente em consequência de, ou com vista a evitar, os efeitos dos conflitos armados, situações de violência generalizada, violações dos direitos humanos, calamidades humanas ou naturais, e que não tenham atravessado uma fronteira internacionalmente reconhecida de um Estado.

Já os migrantes de sobrevivência, segundo Betts (2010b, p. 363-364), são "as pessoas inseridas dentro de uma categoria mais ampla que atual- 
mente atravessam uma fronteira internacional e precisam de proteção por causa de graves privações de direitos humanos". Segundo Correa et al. (2015, p. 224-225), "a interação da combinação de desastres ambientais, Estados frágeis e ausência de subsistência culminam na necessidade de proteção por parte da comunidade internacional".

Primeiramente, quanto aos refugiados convencionais, pode-se destacar o caso dos sírios. No âmbito brasileiro, o Comitê Nacional para os Refugiados (CONARE) aprovou a Resolução Normativa n. 17, de 20 de setembro de 2013, que dispõe sobre a concessão de visto apropriado a individuos forçadamente deslocados por conta do conflito armado na República Árabe Síria, em conformidade com a antiga Lei n. 6815/1980 (antigo Estatuto do Estrangeiro) e seu Decreto regulamentador n. 86715/1981. A resolução mencionada leva em consideração a crise humanitária de grandes proporções, resultante do conflito na Síria, e as dificuldades para conseguirem se deslocar, inclusive, na impossibilidade de cumprir os requisitos regularmente exigidos para a concessão de visto. Nesse sentido, seu artigo $1^{\circ}$ reza que

poderá ser concedido, por razões humanitárias, $\mathrm{o}$ visto apropriado, em conformidade com a Lei $n^{\circ} 6.815$, de 19 de agosto de 1980, e do Decreto n. 86.715, de 10 de dezembro de 1981, a indivíduos afetados pelo conflito armado na República Árabe Síria que manifestem vontade de buscar refúgio no Brasil (BRASIL, 2013).

A Resolução supramencionada teve prazo prorrogado por 2 (dois) anos por meio da Resolução Normativa do CONARE n. 20, publicada no Diário Oficial da União em 22 de setembro de 2015. Vale mencionar, ainda, que a concessão do visto humanitário para os sírios leva em conta as situações específicas em zonas de conflito e segue os mesmos procedimentos para a concessão do refúgio.

Já foram concedidos 7.752 vistos nas embaixadas do Brasil no Líbano, na Jordânia e na Turquia, onde estão as unidades consulares brasileiras próximas ao conflito na Síria (BRASIL, 2015). O ACNUR (2016) registrou que até abril de 2016, o número de refugiados sírios em território brasileiro era de 2.298 pessoas.
Em segundo, vale destacar o caso dos refugiados congoleses no Brasil. O conflito atual na República Democrática do Congo tem ocasionado o deslocamento forçado de milhares de pessoas em virtude dos conflitos internos, e da instabilidade politica e militar que assolam esse pais, principalmente nas províncias de Kasai, Kasai Central, Kasai Oriental, Lomami e Sankuru.

Muitos congoleses têm solicitado a condição de refugiado no Brasil, tendo o CONARE analisado cada pedido individualmente. O ACNUR (BRASIL, 2018, p. 12-13, 17) registrou que, entre 2007 e 2017, o número de refugiados congoleses em território brasileiro era de 953 pessoas (13\% do total), sendo que apenas em 2017 o CONARE reconheceu 106 congoleses ( $18 \%$ do total do ano) como refugiados, dos 587 reconhecimentos do ano. A escolha do Brasil como país de destino se dá pelo fato da existência de relações familiares ou de parcerias (VIEIRA, 2015, p. 63).

Em terceiro, no que diz respeito aos migrantes por sobrevivência (BETTS, 2013), pode-se destacar o caso dos migrantes haitianos. O Haiti foi devastado por um forte terremoto em janeiro de 2010, que fez com que milhares de pessoas se deslocassem forçadamente para outros países, como o Brasil, em busca de abrigo. Por não atender aos critérios estabelecidos na Convenção de 1951 (ampliada pelo Protocolo Adicional de 1967), nem na Declaração de Cartagena de 1984, o CONARE encaminhou ao CNIg, com base na Resolução Recomendada n 08/06 (BRASIL, 2006), para que a matéria fosse apreciada.

O CNIg, por sua vez, criou o Grupo de Trabalho Haitianos no Brasil, que propôs que fossem concedidas autorizações por questões humanitárias a esse grupo de pessoas. Assim, o CNIg aprovou a Resolução Normativa n 97, de 12 de janeiro de 2012, considerando razões humanitárias, "aquelas resultantes do agravamento das condições de vida da população haitiana em decorrência do terremoto ocorrido naquele país em 12 de janeiro de 2010", conforme reza seu parágrafo único do artigo $1^{\circ}$ (BRASIL, 2003).

Nesse sentido, poderia ser concedido o visto permanente (para estrangeiro que pretendesse 
fixar-se definitivamente no Brasil) previsto no art. 16 da Lei n 6.815, de 19 de agosto de 1980, por razões humanitárias, condicionado ao prazo de 5 (cinco) anos, nos termos do art. 18 da mesma Lei, circunstância que constaria da Cédula de Identidade do Estrangeiro.

Saliente-se que o artigo $1^{\circ}$ da Resolução Normativa n. 17/2013 dispunha sobre concessão de visto apropriado a individuos forçadamente deslocados por conflitos armados na República Árabe Síria, conforme a revogada Lei 6.815/1980 (antigo Estatuto do Estrangeiro) e seu também extinto decreto regulamentador n. 86.715/81.

Em virtude da constante situação de vulnerabilidade dos haitianos e com a finalidade de garantir a entrada regular dessas pessoas, o governo brasileiro, por meio do CNIg, concedeu consecutivas prorrogações normativas da Resolução Normativa CNIg n. 97/2012 por mais 12 meses, permitindo, assim, a expedição do visto em caráter humanitário, a saber: Resolução Normativa n. 106, publicada no Diário Oficial da União em 25 de outubro de 2013 (BRASIL, 2013); Resolução Normativa n. 113, publicada no Diário Oficial da União, em 15 de dezembro de 2014 (BRASIL, 2014); Resolução Normativa n. 117, publicada no Diário Oficial da União, em 17 de agosto de 2015 (BRASIL, 2015); e Resolução Normativa n. 123, publicada no Diário Oficial da União, em 20 de setembro de 2016 (BRASIL, 2016).

O Brasil emitiu, até julho de 2015, cerca de 26 mil vistos humanitários para migrantes haitianos, sendo 20 mil na embaixada do Brasil em Porto Príncipe, no Haiti e, aproximadamente, 6 mil em Quito, no Equador (BRASIL, 2016). Contudo, entre 2010 e 2017, apenas dois haitianos foram reconhecidos como refugiados, um em 2008 e outro em 2016, dos 52.243 que solicitaram a condição jurídica de refúgio (BRASIL, 2018, p. 18).

Outro caso que se enquadra como migrantes por sobrevivência, são os ganeses que, em decorrência da Copa do Mundo da Federação Internacional de Futebol (FIFA), realizada no Brasil em 2014, obtiveram o visto de turismo para o periodo da Copa. Contudo, ao chegar ao Brasil, eles requereram ao governo brasileiro o reconhecimento da condição de refugiado. Perseguições religiosas (entre cristãos e mulçumanos) constam no topo da lista de motivos que levaram ganeses a requererem refúgio no país sul-americano. Além do mais, questões referentes à discriminação e à perseguição quanto à orientação sexual podem ter sido os motivos para a solicitação de refúgio (CAVALHEIRO, 2014).

Por não ter os critérios estabelecidos na Convenção de 1951, a concessão do status de refugiado não pode ser concedida, o que acarretava situações de documentação precária e com a possibilidade de retornarem aos seus paises de origem. Nesse sentido, foi concedida autorização de permanência publicada no Diário Oficial da União no dia 16 de fevereiro de 2016, com base na Resolução Normativa n. 28, de 25 de novembro de 1998 (BRASIL, 1998), que trata de casos considerados omissos ou especiais, permitindo, assim, a autorização de trabalho para investidor estrangeiro (pessoa física) com fins de obter visto permanente a partir de um viés humanitário. Em virtude disso, o CNIg aprovou os pedidos de permanência no Brasil de 330 ganeses que já viviam no Brasil (BRASIL, 2016).

Ainda sobre os ganeses, saliente-se que entre 2011 e 2017 o Brasil recebeu, conforme dados publicados pelo Ministério da Justiça (BRASIL, 2018, p. 16), 126.102 mil solicitações de reconhecimento da condição de refugiado, havendo ainda 84.162 mil em trâmite, incluindo-se haitianos e venezuelanos. Destes, cerca de 3\% são de ganeses (3.783).

Por fim, como exemplo dos deslocados internos ambientais, tem-se o caso das pessoas deslocadas em virtude do rompimento da barragem de Fundão, localizada no subdistrito de Bento Rodrigues, próximo ao município brasileiro de Mariana, estado de Minas Gerais. A barragem pertencia à mineradora Samarco, controlada pela empresa brasileira Vale e pela anglo-australiana BHP Billiton. O rompimento, ocorrido em 5 de novembro de 2015, despejou rejeitos de mineração no Rio Doce, atingindo o povoado de Bento Rodrigues. Esse foi o maior desastre envolvendo barragens de rejeito de mineração do mundo, considerando os registros iniciados a partir de 1915 (BOWER ASSOCIATES, 2015). 
Em virtude desse desastre ambiental, muitas casas foram soterradas pela lama, tendo como consequência o deslocamento forçado de várias familias, uma vez que se tornou impossivel a permanência nas residências. "A ausência de um plano de emergência efetivo e a incapacidade do Estado e da empresa de prestarem o devido atendimento às vítimas aumentou consideravelmente o sofrimento dos atingidos pelo rejeito" (MILANEZ; LOSEKANN, 2016, p. 11).

O governo do estado de Minas Gerais, em um relatório sobre a avaliação dos efeitos e desdobramentos do rompimento da Barragem de Fundão, apontou que esse desastre deixou 17 mortos, mais de 600 pessoas desabrigadas e desalojadas, e milhares de pessoas sem água, gerando graves danos ambientais e socioeconômicos à toda a Bacia do Rio Doce (GOVERNO DO ESTADO DE MINAS GERAIS, 2016).

As medidas adotadas pelo governo brasileiro no que concerne aos deslocados ambientais do desastre de Mariana foram apenas institucionais, como a disponibilização de viaturas do Exército, aeronaves da Força Aérea Brasileira e militares para o apoio às buscas; a liberação antecipada do recursos do Bolsa Família; o reconhecimento da situação de emergência, por meio da portaria n. 222, da Secretaria Nacional de Proteção e Defesa Civil publicada no Diário Oficial da União em 10 de novembro de 2015 (BRASIL, 2015); e a liberação de nove milhões adicionais ao seu orçamento para adoção de medidas emergenciais em Minas Gerais (BRASIL, 2015).

Como observado nos casos mencionados, existem discrepâncias do governo brasileiro na proteção aos refugiados convencionais (como os refugiados sírios e congoleses) e a migrantes de sobrevivência (os ganeses, os deslocados ambientais internacionais haitianos e os deslocados internos ambientais do Rio Doce), confirmando, assim, a existência de um regime híbrido de proteção a deslocados no território brasileiro.

Adicione-se, a título ilustrativo, o atual caso dos venezuelanos no Brasil (que computa 33\% das atuais solicitações de refúgio em trâmite), em que a grande maioria tem solicitado a condição de refugiado e alguns outros o visto de residente temporário (já com base no artigo 14 da nova lei de migração (n. 13445/2017). Numericamente, apenas 18 venezuelanos foram reconhecidos como refugiados no Brasil, entre 2010 e 2017 , sendo (4) quatro em 2015 e 14 em 2016, do total de 22.315 mil que ingressaram no território brasileiro no periodo, sendo que 17.865 mil deles entraram no ano de 2017 (BRASIL, 2018, p. 19). Ou seja, os venezuelanos ainda se encontram em situação de vulnerabilidade juridica, em que a grande maioria possui apenas um protocolo de refúgio, documento frequentemente desconhecido pelos prestadores de serviço público e privado no Brasil, dificultando sua integração no país, como abertura de conta bancária, matrícula em escolas, aluguel da casa e acesso aos serviços de saúde.

Uma das formas de solucionar essa situação, em virtude de ausência de um regime internacional padronizado para proteção de todas estas categorias de pessoas, é o regime stretching (BETTS, 2010a, 2013), que os autores deste artigo defendem ser a solução para o caso brasileiro, inclusive por auxiliar a garantir segurança humana aos nacionais e aos estrangeiros em situação de vulnerabilidade no Brasil, independentemente da condição de refugiado ou de posse de visto com autorização para residência.

\section{Regime Stretching para proteção dos refugiados e deslocados ambientais no Brasil}

A atual crise das migrações é fato público e notório em todo o mundo, do Norte ao Sul Global. Contudo, segundo Betts (2014, p. 76-79), instituições surgem cotidianamente para lidar com a crise e reduzir suas consequências para migrantes e deslocados, apesar de que as normas e as instituições já existentes deveriam apenas se adaptar ou alargar seu escopo de atuação (stretch), para resolver esses desafios, como o surgimento de deslocados ambientais, sem precisar de reformas estruturais ou um novo regime internacional. $\mathrm{O}$ regime stretching é necessário para que as instituições se adaptem aos novos desafios.

As instituições atuais não previram o surgimento de certas categorias de deslocados, como os 
ambientais, cujo deslocamento é causado pela necessidade de sobrevivência. Por isso, essa categoria pode ser classificada como migrantes de sobrevivência (survival migrants), porque, segundo Betts (2014, p. 77), esses ficam fora do escopo de proteção do regime internacional de refugiados, embora estes individuos sejam protegidos por normas de direitos humanos, normas ambientais e ações humanitárias.

A necessidade de proteção, portanto, poderia ser suprida com o regime stretching, ou seja, quando um regime pode adaptar-se em nivel nacional de implementação, mesmo na ausência de adaptação nos niveis de negociação ou institucionalização internacional (BETTS, 2014, p. 79). Nas palavras de Betts (2010a, p. 2, tradução nossa), regime stretching pode ser definido como "o ponto em que o escopo de um regime em nivel nacional ou local assume tarefas adicionais ou suplementares não prescritas em nivel global".2 Nesse sentido, ele (2010a, p. 2, tradução nossa) ressalta que

[o] alongamento do regime pode ser distinguido da 'conformidade' na medida em que a conformidade implica alcançar os padrões mínimos de comportamento prescritos ou proscritos pelo "ponto de referência" de um regime, enquanto o alongamento implica a realização de tarefas adicionais ou suplementares que excedam o que é prescrito ou proscrito pelo " ponto de referência " do regime. ${ }^{3}$

Para Betts (2010a, p. 5), a adaptação de um regime internacional, particularmente o regime internacional dos refugiados, em termos de normas e organizações internacionais, pode ocorrer nos niveis de negociação internacional, institucionalização e implementação local, conforme a tabela abaixo:

TABELA 1 - Adaptação de um regime internacional

\begin{tabular}{lll}
\hline & Normas & Organizações internacionais \\
\hline Negociação internacional & Negociação de tratados & Negociação do estatuto \\
Institucionalização & Legislação & Interpretação do mandato \\
Implementação & Políticas públicas & Prática \\
\hline
\end{tabular}

Fonte: Betts (2010a, p. 7. tradução nossa).

A Tabela 1 explica que, em se tratando de normas internacionais, a negociação de tratados, a institucionalização de leis e a implementação de políticas públicas em esfera local podem ser suficientes e eficientes para solucionar dilemas locais, sem haver a necessidade de criar um novo regime internacional. O mesmo ocorre para as organizações internacionais, cujos estatuto, interpretação do mandato e implementação prática podem adaptar-se em contexto local com eficiência.

A adaptação, de normas, instituições e políticas já existentes, ao invés de serem criadas novas, resulta do surgimento de novos desafios que os regimes não previram, como no caso do Brasil, a criação das resoluções do CNIg e do CONA$R E$, elencadas acima, para, como precedentes jurídicos, conceder visto permanente por motivo humanitário aos haitianos acolhidos pelo Brasil após o terremoto de 2010 e o visto humanitário aos sírios perseguidos pelo regime governamental.

Assim, o alargamento do atual regime (regime stretching) internacional, primeiramente, em nivel de implementação local, utiliza as normas e as estruturas governamentais já existentes, como os tratados internacionais ratificados e incorporados pelo Estado. No Brasil, ele pode utilizar a estrutura do CONARE, do CNIg, do Ministério do Trabalho e Emprego, suas parcerias com ONG etc., para

\footnotetext{
2 Do original: IT]he degree to which the scope of a regime at the national or local level takes on additional or supplementary tasks not prescribed at the global level

3 Do original: Regime stretching can be distinguished from 'compliance" insofar as compliance implies attaining the minimum standards of behaviour prescribed or proscribed by the 'benchmark' of a regime, while stretching implies undertaking additional or supplementary tasks that exceed what is prescribed or proscribed by the "benchmark" of the regime.
} 
adaptar o regime internacional dos refugiados e outras normas dos diversos regimes de direitos humanos e de direito ambiental para proteger os deslocados ambientais e os deslocados internos ambientais em seu território.

Em segundo, em nivel de institucionalização, a existência de normas e de práticas de políticas públicas podem ser incorporadas aos ordenamentos jurídicos e às políticas públicas estatais (BETTS, 2014, p. 79). No contexto brasileiro, os migrantes e deslocados possuem, por exemplo, direito ao trabalho, com carteira de trabalho assinada e todos os direitos trabalhistas, cadastro de pessoa física, Bolsa Familia, Sistema Único de Saúde (i.e., educação pública), direito à assistência da defensoria pública da União e benefício constitucional da prestação continuada (i.e., garantia de um salário minimo aos que comprovem não possuir meios de prover sua própria manutenção nem de tê-la provida por sua familia, conforme, entre outros, arts. $5^{\circ}, 6^{\circ}$ e 203, V, da CR/88, validado pelo STF em seu RE 587.970, e art. $4^{\circ}$, VIII da Lei 13.445/2017).

Cabe salientar que a concessão de beneficios assistenciais aos refugiados é atual e se encontra no julgamento do Recurso Especial 587970 pelo Supremo Tribunal Federal que, em sede de repercussão geral, decidiu por afastar a limitação apontada, passando a permitir a prestação do benefício de prestação continuada ao estrangeiro e ao refugiado, conforme menciona Santiago (2016).

Há, ainda, a novidade da nova Lei de Migração Brasileira (Lei n. 13.445/2017), cujo decreto regulamentador poderá suprir as falhas existentes e ampliar direitos, já previstos e garantidos constitucionalmente, que reduzam os obstáculos à integração dos migrantes e deslocados no Brasil, como os direitos à liberdade de associação civil e participação política e a regularização da condição migratória no território nacional.

E, por fim, em nivel de negociações/acordos internacionais, o Brasil poderia consolidar, via ordenamento jurídico doméstico, normas que se coadunem com os padrões internacionais de proteção, criando estruturas de coordenação ou melhorando as já existentes, como a concessão de visto aos haitianos na Embaixada do Brasilem Port-au-Principe.
O regime stretching e a adaptação das normas em nivel nacional/local são sempre motivados pelos interesses da elite nacional em manter seu poder politico e econômico (BETTS; ORCHARD, 2014). Contudo, há vários incentivos para convencer a elite governamental a conduzir a adaptação normativa necessária, como opinião pública, sociedade civil e interesses comerciais.

Nesse sentido, o governo poderia convencer a elite de que adaptar normas e instituições existentes e implementar acordos internacionais em nivel local seria uma forma, por exemplo, de melhorar a imagem do Brasil no exterior e obter o tão sonhado assento permanente no Conselho de Segurança das Nações Unidas, resultante de futura reforma no Órgão (PACIFICO et al., 2015, p. 139-151); de melhorar segurança estatal, reduzindo a criminalidade aumentada com casos de racismo e discriminação contra migrantes; de aumentar o número de parceiros comerciais e a cooperação, bem como pelos conceitos de direitos humanos e de segurança humana, dentre outros argumentos possiveis.

Os direitos humanos, por exemplo, são vistos como algo instituido a partir da Revolução Francesa, partindo da garantia de uma condição cidadã, principalmente aos cidadãos franceses. Entretanto, conforme as conquistas napoleônicas ganhavam boa parte dos países, os ideais da Revolução Francesa ganhavam estes lugares, ou seja, a ideia de cidadania não pertencia mais somente aos franceses, mas àqueles lugares em que o conceito de cidadania ia sendo incorporado (BUZAN; HANSEN, 2012, p. 63).

Posteriormente, com a criação da Organização das Nações Unidas, o conceito dos Direitos Humanos se faz observar em todo o Globo, ao menos como principio, e, o que é mais importante, além de fronteiras nacionais, ou seja, o fato de ser humano já é o bastante para que se tenha direitos humanos. Essa ideia parece tautológica, mas a humanização é um princípio que coloca o ser humano frente a frente com o princípio ético de se considerar como "humano" aquele que poder-se-ia ser considerado menos do que os nacionais, simplesmente por não ser da mesma nação, ou por possuir etnia diferenciada. 
Isto se conecta com a ideia de Segurança Humana, que nasce no Programa das Nações Unidas para o Desenvolvimento, em 1994, apontando o indivíduo como objeto de referência da segurança, já que a segurança dos Estados, individualmente, e a Internacional, focada nas relações de poder entre eles, simplesmente, não cuida (BUZAN; HANSEN, 2012, p. 218, 308-309). Isso possibilita o exercício de que se olhe para os despossuidos de humanidade, por privações as mais diversas, com um olhar de proteção e de cuidado, criando alternativas aos Estados.

Nesse sentido, este tipo de pensamento traduz a ideia de uma união global que desconsidera fronteiras, já que a interconexão independe de divisões imaginárias, ou construidas artificialmente, já que os seres humanos ultrapassam essas fronteiras a todo o tempo, fugindo das mais diversas intempéries, sejam elas políticas, econômicas, perseguição, escassez de recursos ou sobrevivência em geral (BOOTH, 1991, p. 322), como se vê no caso da Samarco (Brasil), ou seja, mesmo dentro das fronteiras há diversos fenômenos que ocorrem, despossuindo pessoas, nacionais, que não recebem o devido cuidado e atenção que deveriam.

Portanto, pensar regimes de proteção a deslocados, criando possibilidades de assistência e de inclusão, possibilitando a emancipação e a autonomia, indo além da simples sobrevivência, a esses diversos tipos de deslocados, sejam eles nacionais ou estrangeiros, sejam motivados por catástrofes ambientais ou por crises e guerras, é fundamental para se pensar no mundo de proteção e de inclusão proposto por Booth (2007, p. 95-148), ou seja, fornecendo acolhimento com integração aos newcomers, com base nos princípios da dignidade da pessoa humana e da não devolução ao país em que a sobrevivência do imigrante ou deslocado se encontra em risco (i.e., non refoulement).

\section{Considerações finais}

Por fim, haja vista a crise migratória global, a dificuldade da comunidade internacional em alterar o regime atual ou criar um novo regime e, em se tratando de Brasil, a crise migratória causada pela entrada de venezuelanos no país, parece fácil concordar com Betts que regime stretching pode ser a solução, tendo o Brasil já usado deste instrumento com sucesso, ao conceder visto permanente por motivo humanitário aos haitianos chegados ao Brasil após o terremoto de 2010.

A implementação padronizada da proteção, contudo, que, no momento, se faz de forma hibrida para refugiados, deslocados ambientais internos e deslocados ambientais internacionais, em nivel de implementação local, de institucionalização e de acordos internacionais, já em vigor no Brasil, poderia ser uma solução a curto prazo, particularmente em virtude da publicação da nova Lei de Migração n. 13.445/2017 e de seu Decreto Regulamentador n. 9.199/2017. que mantém em esferas distintas a proteção e o acolhimento do refugiado convencional (i.e., com base na Conveção de Genebra de 1951) e dos migrantes, independentemente de serem esses voluntários ou forçados.

Em suma, o Brasil está no momento de adaptar o regime internacional (normas e instituições) em prática doméstica para proteger os migrantes de sobrevivência (survival migrants), ou seja, aquelas pessoas que fogem em virtude de privações dos direitos mais básicos à sobrevivência, que deveriam ser acolhidos, ao invés de serem perseguidos.

\section{Referências}

ACNUR. Convenção Relativa ao Estatuto de Refugiados Genebra: ACNUR, 1951

ACNUR. Protocolo de 1967 Relativo ao Estatuto dos Refugiados. Nova York: ACNUR, 1967.

ACNUR. Declaração de Cartagena de 1984. Cartagena: ACNUR, 1984.

ACNUR. Dados sobre refúgio no Brasil. ACNUR, Brasília, 2018. Disponivel em: http://www.acnur.org/portugues/ recursos/estatisticas/dados-sobre-refugio-no-brasil. Acesso em: 11 nov. 2019.

BETTS, A. Regime Stretching: How International Institutions Adapt at Implementation. Oxford: University of Oxford, Politics Department, 2010a. Lecture.

BETTS, A. 2010b. Survival Migration: a new protection framework. Global Governance: a review of multilateralism and international organizations, New York, v. 16, n. 3. p. 361-382, 2010b. 
BETTS, A. Survival Migration: Failed Governance and the Crisis of Displacement. Ithaca: Cornell University Press, 2013

BETTS, A. The Global Governance of Crisis Migration. Forced Migration Review, Oxford, v. 45, n. 1, p. 76-79, 2014

BETTS, A; ORCHARD, P. (ed.). Implementation and World Politics: How International Norms Change Practice. Oxford: OUP, 2014

BOOTH, K. Security and Emancipation. Review of International Studies, Cambridge, v. 17, p. 313-326, 1991.

BOOTH, K. Theory of world security. Cambridge: Cambridge University Press, 2007.

BOWKER ASSOCIATES. Samarco dam failure largest by far in recorded history. In: Bowker Associates. Portland, 12 dez. 2015. Disponivel em: https://lindsaynewlandbowker.wordpress.com/2015/12/12/samarco-dam-failure-largest-by-far-in-recorded-history. Acesso em: 21 set. 2019.

BRASIL. Conheça 12 ações do governo para enfrentar os impactos da tragédia de MG e ES. In: Portal Brasil. Brasilia, 23 nov. 2015. Disponivel em: http://www.brasil. gov.br/defesa-e-seguranca/2015/11/conheca-12-acoes-do-governo-para-enfrentar-os-impactos-da-tragedia-de-mg-e-es. Acesso em: 11 nov. 2019.

BRASIL. Ministério da Justiça. Refúgio em Números. Brasilia: MJ, 2015.

BRASIL. Comitê Nacional para os Refugiados. Resolução Normativa n. 08, de 19 de dezembro de 2006. Dispõe sobre pedidos de refúgio apresentados ao Comitê Nacional para os Refugiados - CONARE, que a critério deste, possam ser analisados pelo Conselho Nacional de Imigração - CNIg como situações especiais. Brasilia: CONARE, 2006. Disponivel em: http://WwW. acnur.org/t3/fileadmin/Documentos/BDL/2014/9720. pdf? view=1. Acesso em: 20 set. 2019

BRASIL. Comitê Nacional para os Refugiados. Resolução Normativa $n .17$ de 20 de setembro de 2013. Dispõe sobre a concessão de visto apropriado, em conformidade com a Lei $n^{\circ} 6.815$, de 19 de agosto de 1980, e do Decreto 86.715, de 10 de dezembro de 1981, a individuos forçosamente deslocados por conta do conflito armado na República Árabe Síria. Brasília: CONARE, 2013. Disponivel em: https://www.legisweb.com.br/ legislacao/?id=258708. Acesso em: 20 set. 2019

BRASIL. Comitê Nacional para os Refugiados. Resolução Normativa n. 20 de 21 de setembro de 2015. Prorroga a vigência da Resolução Normativa $n^{\circ} 17$, de 20 de setembro de 2013, e dá outras providências. Brasília: CONARE, 2015. Disponivel em: https://www. legisweb. com.br/legislacao/?id=303612. Acesso em: 20 set. 2019

BRASIL. Conselho Nacional de Imigração. Resolução Normativa CNIg n. 28 de 25 de novembro de 1998. Disciplina a concessão de Autorização de Trabalho para fins de obtenção de visto permanente, para investidor estrangeiro - pessoa física. Brasilia: CNIg, 1998. Disponivel em: https://www.legisweb.com.br/legislacao/?id=96399. Acesso em: 20 set. 2019.
BRASIL. Conselho Nacional de Imigração. Resolução Normativa CNIg n. 97 de 12 de janeiro de 2012. Dispõe sobre a concessão do visto permanente previsto no art. 16 da Lei n 6.815, de 19 de agosto de 1980, a nacionais do Haiti. Brasilia: CNIg, 2012. Disponivel em: https://www.legisweb.com.br/legislacao/?id=116083. Acesso em: 20 set. 2019.

BRASIL. Conselho Nacional de Imigração. Resolução Normativa CNIg n. 106 de 24 de outubro de 2003. Prorroga a vigência da Resolução Normativa n 97 , de 12 de janeiro de 2012. Brasilia: CNIg, 2003. Disponivel em https://www.legisweb.com.br/legislacao/?id=261070. Acesso em: 21 set. 2019

BRASIL. Conselho Nacional de Imigração. Resolução Normativa CNIg n. 113 de og de dezembro de 2014. Prorroga a vigência da Resolução Normativa $n^{\circ}$ 97, de 12 de janeiro de 2012. Brasília: CNIg, 2014. Disponivel em: https://www.legisweb.com.br/legislacao/?id=278602 . Acesso em: 21 set. 2019

BRASIL. Conselho Nacional de Imigração. Resolução Normativa CNIg n. 117 de 12 de agosto de 2015. Prorroga a vigência da Resolução Normativa $n^{\circ} 97$, de 12 de janeiro de 2012. Brasília: CNIg, 2015. Disponivel em: https://www.legisweb.com.br/legislacao/? id =30170. Acesso em: 21 set. 2019

BRASIL. Secretaria Nacional de Proteção e Defesa Civil. Portaria n. 222, de 10 de novembro de 2015. Reconhece situação de emergência por procedimento sumário no Municipio de Mariana-MG. Brasilia: SEDEC, 2015. Disponivel em: http://pesquisa.in.gov.br/imprensa/jsp/visualiza/index.jsp?jornal=1\&pagina=28\&data=11/11/2015. Acesso em: 21 set. 2019

BRASIL. Conselho Nacional de Imigração. Resolução Normativa CNIg n. 123 de 13 de setembro de 2016. Prorroga a vigência da Resolução Normativa $n^{\circ}$ 97, e 12 de janeiro de 2012. Brasília: CNIg, 2016. Disponivel em: https://www.legisweb.com.br/legislacao/?id=328777. Acesso em: 21 set. 2019

BRASIL. Secretaria Nacional de Proteção e Defesa Civil Portaria n. 15, de 8 de fevereiro de 2017. Reconhece situação de emergência em municipios. Brasília: SEDEC, 2017. Disponivel em: http://pesquisa.in.gov.br/ imprensa/servlet/INPDFViewer?jornal=1\&pagina=15\&data $=10 / 02 / 2017 \&$ captchafield=firistAccess. Acesso em: 21 set. 2019 .

BRASIL. Ministério da Justiça. Brasil prorroga por dois anos emissão de vistos especiais para refugiados sírios. MJ, Brasilia, 21 set. 2015. Disponivel em: http://www. brasil.gov.br/cidadania-e-justica/2015/og/brasil-prorroga-por-dois-anos-emissao-de-vistos-especiais-para-refugiados-sirios. Acesso em: 21 set. 2019.

BRASIL. Ministério da Previdência Social. Trabalho: Governo concede residência para 330 ganeses que moram no Distrito Federal. Brasilia, 3 mar. 2016. Disponivel em: http://www.previdencia.gov.br/2016/03/trabalho-governo-concede-residencia-para-330-ganeses-que-moram-no-distrito-federal/. Acesso em: 21 set. 2019. 
BRASIL. Ministério do Trabalho. Concessão de visto humanitário para haitianos é prorrogada. Brasília, 23 dez. 2017. Disponivel em: http://www.brasil.gov.br/ cidadania-e-justica/2015/08/concessao-de-visto-humanitario-para-haitianos-e-prorrogada. Acesso em: 10 set. 2019

BUZAN, B.; HANSEN, L. A evolução dos Estudos de Segurança Internacional. São Paulo: UNESP, 2012.

CAVALHEIRO, A. Ganeses no Brasil: uma Análise do pedido de refúgio. 2014. Monografia (Curso de Graduação em Direito) - UFSC, Florianópolis, 2014.

CORREA, M. S. et al. Migração por sobrevivência: Soluções brasileiras. REMHU, Brasília, v. 23, n. 44, p. 221236, 2015

GOVERNO DO ESTADO DE MINAS GERAIS. Relatório: Avaliação dos efeitos e desdobramentos do rompimento da Barragem de Fundão em Mariana-MG. Belo Horizonte: Secretaria de Estado de Desenvolvimento Regional, Política Urbana e Gestão Metropolitana, 2016.

MILANEZ, B; LOSEKANN, C. (ed.). Desastre no Vale do Rio Doce. Antecedentes, impactos e ações sobre a destruição. Rio de Janeiro: Folio Digital: Letra e Imagem, 2016.

ONU. ACNUR. Principios Orientadores relativos aos Deslocados Internos. Colômbia: Gabinete das Nações Unidas para a Coordenação dos Assuntos Humanitários, 1998.

PACÍFICO, A. P. O capital social dos refugiados: bagagem cultural e políticas públicas. Maceió: Edufal, 2010.

PACÍFICO, A. P; RAMOS, E. P. Humanitarian Asylum for Forced Migrants: the Case of Haitians 'Arrival in Brazil. In: GAUCl, J. P.; GIUFFRE, M.; TSOURDI, E. L. (ed.). Exploring the Boundaries of Refugee Law: Current Protection Challenges. International Refugee Law Series. Leiden: Brill Nijhoff, 2015. p. 219-239.

PACIFICO, A. P. et al. The migration of Haitians within Latin America: significance for Brazilian law and policy on asylum and migration. In: CANTOR, D. J.; FREIER, L. F.; GAUCl, J. P. (ed.). A Liberal Tide: immigration and asylum law and policy in Latin America. London, UK: Institute of Latin American Studies, SAS, University of London, UK, 2015. p. 139-151.

PACÍFICO, A. P; GAUDENCIO, M. R. B. A proteção dos deslocados ambientais no regime internacional dos refugiados. REMHU, Brasília, v. 22, n. 43, p. 133-148, 2014.

PACÍFICO, A. P; PINHEIRO, T. K. F. O status do imigrante haitiano no Brasil após o terremoto de 2010 sob a perspectiva do Pós-Estruturalismo. Perspectivas do Desenvolvimento, Brasília, v. 1, n. 1, p. 107-125, 2013.

SANTIAGO, L. T. Direito dos refugiados à assistência social no Brasil. Extensão em Ação, Fortaleza, v. 1, n. 13. p. 16-30, 2016.

SOUZA, J. F. V. Os refugiados ambientais no Brasil: Uma leitura sobre a construção de barragens, geração de energia, restauração da dignidade e cidadania. In: CONGRESSO DO CONSELHO NACIONAL DE PESQUISAE PÓS-GRADUAÇÃO EM DIREITO, 21., João Pessoa. Anais [...]. João Pessoa: Conselho Nacional de Pesquisa e Pós-Graduação em Direito, 2012.
VIEIRA, D. R. Do Congo para o Brasil: as perspectivas de vida e de trabalho de refugiados e solicitantes de refúgio congoleses no Rio de Janeiro. 2015. Dissertação (Mestrado em Antropologia) - UFPE, João Pessoa, 2015.

\section{Andrea Pacheco Pacífico}

Doutora em Ciências Sociais pela Pontificia Universidade Católica de São Paulo (PUC/SP), em São Paulo, SP, Brasil; mestre em Direito Internacional e Politica/ Relações Internacionais pela Universidade de Lancaster (Inglaterra), em Lancaster, Inglaterra, Reino Unido; professora na Universidade Estadual da Paraiba (UEPB), em João Pessoa, PB, Brasil.

\section{Thalita Franciely de Melo Silva}

Mestre em Relações Internacionais pela Universidade Estadual da Paraíba (UEPB), em João Pessoa, PB, Brasil; doutoranda em Ciência Política pela Universidade Federal de Pernambuco (UFPE), em Recife, PE, Brasil; professora da Universidade Estadual da Paraiba (UEPB), em João Pessoa, PB, Brasil.

\section{Paulo Roberto Loyolla Kuhlmann}

Doutor e mestre em Ciência Política pela Universidade de São Paulo (USP), em São Paulo, SP, Brasil; professor na Universidade Estadual da Paraíba (UEPB), em João Pessoa, PB, Brasil.

\section{Endereço para correspondência}

Andrea Pacheco Pacifico/Thalita Franciely de Melo Silva/ Paulo Roberto Loyolla Kuhlmann

Universidade Estadual da Paraíba

Campus V - Curso de Relações Internacionais

R. Horácio Trajano de Oliveira, s/n

Cristo Redentor, 58071-160

João Pessoa, PB, Brasil

Os textos deste artigo foram revisados pela Poá Comunicação e submetidos para validação do(s) autor(es) antes da publicação 